Original Article

\title{
Comparative Results of Repair of Ischemic Mitral Regurgitation (IMR): Conventional Against Trans-Septal Approach
}

Ahson Memon ${ }^{1}$, Junaid Ansari', Ghufranullah Khan ${ }^{1}$, Khalid Rasheed ${ }^{1}$, Ali Shan ${ }^{1}$, Imran Ali $^{1}$, Peer Asad Aziz ${ }^{3}$ and Hamid $\mathrm{Ali}^{3}$

1. Tabba Institute of Heart, Karachi, Pakistan

2. LUMHS, Hyderabad

Corresponding Author: ahson@ aeirc-edu.com

\begin{abstract}
Objective Ischemic mitral regurgitation is common and increases mortality, even when mild. (American Heart Association) AHA and European association have both stressed the need of mitral valve repair in patients with moderate or more regurgitation. The aim of this study was to compare the results with the conventional and right atrial trans-septal approach of mitral valve repair in Ischemic Mitral Regurgitation (IMR). Methodology A total of 308 consecutive patients underwent mitral valve repair for IMR, between January 2012 and December 2013 at Tabba Heart Institute. Patients who had at least moderate mitral regurgitation or more mitral regurgitation underwent mitral regurgitation repair. The final decision of mitral valve repair was taken after the intra operative trans-esophageal echocardiography (TEE). Result Total number of patients included in study was222, out of those $153(69.9 \%)$ patients underwent conventional approach and 69 (31.1) patients underwent trans-septal approach. Total $88.2 \%$ patients got off bypass in normal sinus rhythm in conventional approach group, as compared to $82.1 \%$ in transseptal group. $11.8 \%$ and $17.9 \%$ patients got off by pass on pacing in conventional and transseptal approach respectively. 3 patients developed junctional rhythm and 5 patients developed complete heart block in post-operative period in trans-septal approach. Conclusion Right Atrial Trans-septal technique is a good alternative approach that can be used in relatively small atria. It not only provides an excellent exposure to the mitral valve, there also seems to be no associated rhythm disturbances encountered as well.
\end{abstract}

\section{Keywords}

Ischemic Mitral Regurgitation, Mitral Valve Repair, Trans-esophageal Echocardiography, Transseptal technique, conventional approach.

\section{Introduction}

Ischemic mitral regurgitation conveys adverse prognosis doubling the mortality after myocardial infarction. It is common and increases mortality even when mild. AHA and European association have both stressed the need of mitral valve repair in patients with moderate or more regurgitation ${ }^{1}$. Mortality for patients with Coronary Artery Disease (CAD) and IMR remain high regardless of treatment strategy ${ }^{2}$. In majority of patients, with IMR the valve itself is normal in structure but abnormal in function due to ventricular factors $^{3}$. Restrictive mitral annuloplasty with revascularization is considered the best approach to $\mathrm{IMR}^{4}$. Rings, bands and pericardial strips have all been used to perform mitral annuloplasty. Rings and bands have similar result in the success of 
dealing with $\mathrm{IMR}^{5}$. Ischemic mitral regurgitations is an acute event with relatively short history.

The left atrial size is usually small and to obtain a good view to achieve a satisfactory repair remains a challenge. The left atrial or conventional approach is still the most favored approach. The alternative approach being the superior septal or the right atrial trans-septal approach ${ }^{6}$.

Superior septal approach is made by doing a right atriotomy not beyond crista terminalis, an atrial septotomy followed by incision parallel to Super Vena Cava (SVC) on left atrium (LA). Superior septal approach consistently provides a clear and undistorted exposure of valve and its apparatus without undue LA retraction. Certainly, SSA takes longer time and is difficult approach for closure as compared to conventional approach. Studies have been conducted regarding post-operative cardiac rhythm abnormalities with this approach. Rhythm abnormalities include prolonged PR interval, variations in $\mathrm{P}$-wave axis and morphology, junctional rhythm, atrioventricular block, atrial flutter and atrial fibrillation ${ }^{7}$. Transseptal approach incision starts at the lower border of fossa ovalis and continues till the junction of right and left atrium. This can be increased inferiorly through the interatrial septum till reflection near inferior vena cava. This approach is particularly suitable for patients with less favorable anatomy such as; small left atrium and gives an ideal approach to tricuspid and mitral valve. Number of reports have been published for post-operative permanent pacemaker implantation following this approach. Due to such strong association, this is a preferred approach in patients having pre-operative AV block and double-valve involvement from endocarditis ${ }^{8}$.
The aim of this study was to compare the results with the conventional and right atrial trans-septal approach of mitral valve repair in ischemic mitral regurgitation (IMR).

\section{Methods}

A total of 308 consecutive patients underwent mitral valve repair for IMR, between January 2012 and December 2013 at Tabba Heart Institute. Patients who had at least moderate mitral regurgitation or more mitral regurgitation underwent mitral regurgitation repair. Single center experience of one surgeon who were properly trained after attending the academy workshops to rule out surgeon bias. Selective downsizing was used in patients having mitral annular size $>34 \mathrm{~mm}$ on transesophageal echocardiography (TEE). The final decision of mitral valve repair was taken after the intra operative transesophageal echocardiography (TEE). The success of the repair was then assessed with a post repair intra operative TEE.

\section{Operative Technique by Technique (Prof. Meong Gun Song_Seoul.SK):}

In all cases the heart was approached through the standard median sternotomy. After heparinization cardiopulmonary bypass was established with aortic and bicaval right atrial cannulation with SVC and IVC directly cannulated. Antegrade blood cardioplegia was the dominant mode of myocardial protection. Systemic hypothermia was observed at 28c. No topical cooling was used for supplemental protection. Coronary revascularization (CABG) was done first and the mitral valve repair afterwards. The mitral valve repair was done with Prof. Song's Comprehensive Mitral Valve and Apparatus Reconstruction (COMVAR) technique, using varying sizes of Mitral Lift band for supra-annular posterior annuloplasty in all cases. 
COMVAR; technique for mitral valve repair, introduced by Prof. Meong Gun Song from Seoul was practiced in all patients. Use of specific size of flexible band was made. Every band with the help of 6 Ethicon/Ticron suture without pledgets was placed. Placing the band in supra-annular position with each suture reaching the annulus was ensured. Restricting to the posterior annulus only and not going beyond the commissures was ascertained. Atrial closure, de-cannulation and rest of the closure was practiced as per standard.

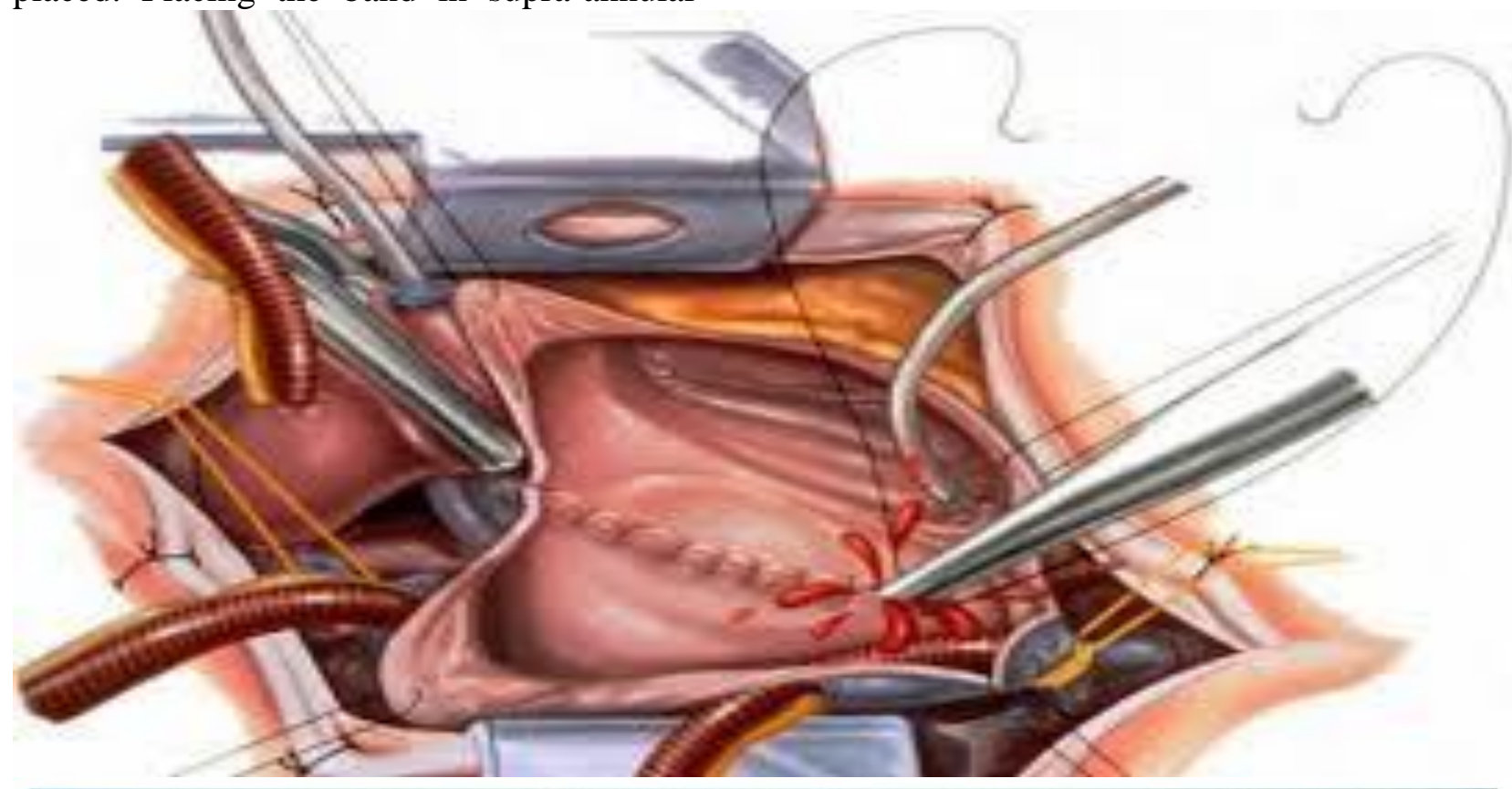

\section{$S-S$ mitra-lift strip}

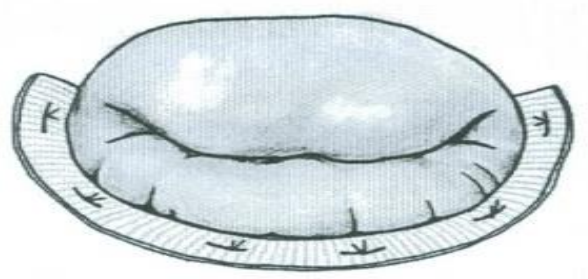

Lifting up the post. annulus

Placement of strip:

left atrial wall to lift up the post. annulus,

not annulus

\section{Results}

Total number of patients included in study were 222, out of those 153 (69.9\%) patients underwent conventional approach and 69
(31.1) patients underwent trans-septal approach. Mean age was $57.38 \pm 12.46$ in conventional approach group and 59.28 \pm 10.9 in trans-septal approach group. In 
gender distribution, males were $50(72.5 \%)$ and females were $19 \quad(27.5 \%)$ in conventional approach group and in transseptal approach group male were 113 (73.9\%) and females were $40(26.1 \%)$.

Pre-operative risk factors were presented between two groups, which included diabetes, hypertension, renal insufficiency, tobacco use, family history of coronary artery disease $(\mathrm{CAD})$, previous $\mathrm{CABG}$, previous PCI, previous heart failure, myocardial infarction and atrial fibrillation. Left ventricular ejection fraction was 38.33 \pm 13.41 in conventional approach group and $34.61 \pm 13.55$ in trans-septal approach group.

Total perfusion time in conventional and trans-septal approach was $113.1 \pm 25.44$ minutes and 111.13 \pm 24.97 minutes respectively (P-Value 0.443). Cross clamp time was $78.0 \pm 16.19$ minutes in conventional and $74.66 \pm 17.93$ minutes in trans-septal approach (P-Value 0.056).

In conventional approach group, in $7.2 \%$ patients $26 \mathrm{~mm}$ band size was used, in $15.9 \%$ patients $28 \mathrm{~mm}$, in $26.1 \% 30 \mathrm{~mm}$, in $21.7 \%$ $32 \mathrm{~mm}, 34 \mathrm{~mm}$ was used in $17.4 \%, 36 \mathrm{~mm}$ was used in $5.8 \%$ and $38 \mathrm{~mm}$ was used in also $5.8 \%$ of patients. Mean $31.33 \pm 3.1$ band size used in conventional approach group. In trans-septal approach 3.9\% used in $26 \mathrm{~mm}$. $28 \mathrm{~mm}$ was used in $15 \%$ patients, 30 mm was used in $26.1 \%, 32 \mathrm{~mm}$ was used in $23.5 \%, 34 \mathrm{~mm}$ was used in $18.3 \%, 36 \mathrm{~mm}$ was used in $9.8 \%$ and $38 \mathrm{~mm}$ was used in $3.3 \%$. Mean $31.59 \pm 2.87$ band size used in conventional approach group.

In conventional approach group, 52.2\% patients had moderate MR preoperatively and $47.8 \%$ patients had severe MR. Whereas, in trans-septal approach patients, 19\% patients had moderate MR and $81 \%$ had severe MR. post repair intra operative TEE showed $95.7 \%$ of patients had < mild MR, $4.3 \%$ had moderate and $0 \%$ had severe MR. where as in trans-septal approach group, $94.1 \%$ had < mild MR, 5.2\% had moderate and $0.7 \%$ had severe MR after repair intra operative Transesophageal Echocardiogram (TEE).

Total $88.2 \%$ patients got off bypass in normal sinus rhythm in conventional approach group, as compared to $82.1 \%$ in trans-septal group. $11.8 \%$ and $17.9 \%$ patients got off by pass on pacing in conventional and trans-septal approach respectively. 3 patients developed junctional rhythm and 5 patients developed complete heart block in post-operative period in transseptal approach.

Table 1: Baseline and Operative characteristics of the patients

\begin{tabular}{lll}
\hline $\begin{array}{l}\text { Baseline and Operative Characteristics of the } \\
\text { Patients }\end{array}$ & $\begin{array}{l}\text { Conventional } \\
\text { Approach } \\
\text { n=69 }\end{array}$ & $\begin{array}{l}\text { Trans-Septal } \\
\text { Approach } \\
\mathrm{n}=153\end{array}$ \\
\hline Male no. (\%) & $50(72.5 \%)$ & $113(73.9 \%)$ \\
$\begin{array}{l}\text { Female no. (\%) } \\
\text { Age, year } \\
\text { Medical \& Surgical History no. (\%) }\end{array}$ & $19(27.5 \%)$ & $40(26.1 \%)$ \\
Tobacco Use & $57.38 \pm 12.46$ & $59.28 \pm 10.9$ \\
Family History of CAD & $26(37.7 \%)$ & $56(36.6 \%)$ \\
Diabetes & $16(23.2 \%)$ & $32(20.9 \%)$ \\
Hypertension & $40(58 \%)$ & $87(56.9 \%)$ \\
\hline
\end{tabular}




\begin{tabular}{lll}
\hline Renal Insufficiency & $24(34.8 \%)$ & $44(28.8 \%)$ \\
Previous CABG & $1(1.4 \%)$ & $1(0.7 \%)$ \\
Previous PCI & $6(8.7 \%)$ & $5(3.3 \%)$ \\
Heart Failure & $19(27.5 \%)$ & $47(30.7 \%)$ \\
\hline Myocardial Infarction & $44(63.8 \%)$ & $102(66.7 \%)$ \\
\hline Atrial Fibrillation & $3(4.3 \%)$ & $3(2 \%)$ \\
Stroke & $2(2.9 \%)$ & $1(0.7 \%)$ \\
Grade III or IV Angina scale no. (\%) & $45(65.2 \%)$ & $94(61.4 \%)$ \\
\hline NYHA class III or IV no. (\%) & $42(60.9 \%)$ & $74(48.4 \%)$ \\
Left Ventricular ejection fraction \% & $38.33 \pm 13.41$ & $34.61 \pm 13.55$ \\
Number of Diseased Coronary Vessels & & \\
One VCAD & $2(2.9 \%)$ & $2(1.3 \%)$ \\
Two VCAD & $7(10.1 \%)$ & $26(17 \%)$ \\
Three VCAD & $51(73.9 \%)$ & $118(77.1 \%)$ \\
Elective Surgery no. (\%) & $41(59.4 \%)$ & $83(54.2 \%)$ \\
Concomitant procedure no. $(\%)$ & & \\
CABG & $61(88.4 \%)$ & $146(95.4 \%)$ \\
Tricuspid Valve Annuloplasty & $5(7.2 \%)$ & $19(12.4 \%)$ \\
AVR & $1(1.4 \%)$ & $2(1.3 \%)$ \\
Other Cardiac Surgery & $5(7.2 \%)$ & $6(3.9 \%)$ \\
\hline
\end{tabular}

* Plus minis values are mean $\pm \mathrm{SD}$.

Table 2: Operative \& Mitral Valve Status

\begin{tabular}{|c|c|c|}
\hline Operative \& Mitral Valve Status & $\begin{array}{l}\text { Conventional } \\
\text { Approach } \\
\mathrm{n}=69\end{array}$ & $\begin{array}{l}\text { Trans-Septal } \\
\text { Approach } \\
\mathrm{n}=153\end{array}$ \\
\hline Perfusion Time min: & $113.1 \pm 25.44$ & $111.13 \pm 24.97$ \\
\hline Cross Clamp Time min: & $78 \pm 16.19$ & $74.66 \pm 17.93$ \\
\hline Initial ICU stay: (Hours) & $37.06 \pm 22.13$ & $41.61 \pm 25.6$ \\
\hline \multicolumn{3}{|l|}{ Band size used no. (\%) } \\
\hline 26 mm & $5(7.2 \%)$ & $6(3.9 \%)$ \\
\hline $28 \mathrm{~mm}$ & $11(15.9 \%)$ & $23(15 \%)$ \\
\hline $30 \mathrm{~mm}$ & $18(26.1 \%)$ & $40(26.1 \%)$ \\
\hline $32 \mathrm{~mm}$ & $15(21.7 \%)$ & $36(23.5 \%)$ \\
\hline $34 \mathrm{~mm}$ & $12(17.4 \%)$ & $28(18.3 \%)$ \\
\hline $36 \mathrm{~mm}$ & $4(5.8 \%)$ & $15(9.8 \%)$ \\
\hline $38 \mathrm{~mm}$ & $4(5.8 \%)$ & $5(3.3 \%)$ \\
\hline mean $\pm \mathrm{SD}$ & $31.33 \pm 3.1$ & $31.59 \pm 2.87$ \\
\hline \multicolumn{3}{|c|}{ Pre-Op Mitral Regurgitation no. (\%) } \\
\hline Moderate & $36(52.2 \%)$ & $29(19 \%)$ \\
\hline Severe & $33(47.8 \%)$ & $124(81 \%)$ \\
\hline
\end{tabular}




\begin{tabular}{lll}
\hline Post Repair Intra-Op TEE Results no. (\%) & & \\
No & $15(21.7 \%)$ & $43(28.1 \%)$ \\
Trace & $36(52.2 \%)$ & $77(50.3 \%)$ \\
Mild & $15(21.7 \%)$ & $24(15.7 \%)$ \\
Moderate & $3(4.3 \%)$ & $8(5.2 \%)$ \\
Severe & $0(0 \%)$ & $1(0.7 \%)$ \\
\hline
\end{tabular}

$*$ Plus minis values are mean $\pm \mathrm{SD}$.

Table 3: Clinical end point, Serious Adverse Event

\begin{tabular}{|lll}
\hline Clinical end point, Serious Adverse Event & $\begin{array}{l}\text { Conventional } \\
\text { Approach } \\
\text { n=68 }\end{array}$ & $\begin{array}{l}\text { Trans-Septal } \\
\text { Approach } \\
\text { n=67 }\end{array}$ \\
\hline Clinical End Points & & \\
\hline Death (during hospital stay) no. (\%) & $7(10.1 \%)$ & $18(11.8 \%)$ \\
\hline $\begin{array}{ll}\text { In Hospital Serious Adverse Event no. (\%) } \\
\text { Any }\end{array}$ & $31(44.9 \%)$ & $72(47.1 \%)$ \\
$\quad$ Reoperation for bleeding Tamponade & $4(5.8 \%)$ & $17(11.1 \%)$ \\
$\quad$ Septicemia & $2(2.9 \%)$ & $6(3.9 \%)$ \\
$\quad$ Postoperative Stroke for $>\mathbf{7 2}$ hours & $2(2.9 \%)$ & $1(0.7 \%)$ \\
$\quad$ Prolonged Ventilation (>24hr) & $12(17.4 \%)$ & $31(20.3 \%)$ \\
$\quad$ Dialysis Newly Required & $2(2.9 \%)$ & $6(3.9 \%)$ \\
$\quad$ Renal Failure & $18(26.1 \%)$ & $38(24.8 \%)$ \\
$\quad$ Atrial fibrillation & $10(14.5 \%)$ & $26(17 \%)$ \\
$\quad$ Ventricular Tachycardia & $3(4.3 \%)$ & $3(2 \%)$ \\
$\quad$ Heart failure & $2(2.9 \%)$ & $5(3.3 \%)$ \\
$\quad$ Multi-system failure & $0(0 \%)$ & $3(2 \%)$ \\
Inotropic used after 24 hrs. & $16(23.2 \%)$ & $54(35.3 \%)$ \\
\hline
\end{tabular}

\section{Discussion}

At our institute we started doing procedure for ischemic mitral regurgitation. In the initial phase we continued with our conventional approach which we were using for mitral valve replacement. We noted that patients with ischemic mitral regurgitation were different to classic valvular cases where left atrial size was much smaller and it was also noted that the vision of mitral valve in this small left atrium was at an angle. At many times, the vision was incomplete. Also it was noted that the annulus was de-shaped so to imagine a repair and assess it after repair become subjective to the pull on the heart which had many variables.

In view of above consideration, we started looking for other possible approaches which will help us overcome these limitations. We came upon trans-septal approach. In this approach we found that we did not necessarily have to pull hard for a view. The view seen was complete without any distortion of the annulus. So to assess the repair and imagination required for the procedures required to obtain it very simple. 
It overcome the limitation of small left atrial size. We were also able to complete tricuspid procedures easily. We were worried about rhythm disturbances as noted by previous authors ${ }^{9}$. The worry of disturbing the nodal artery is managed by keeping the superior limit of the incision, away from the SVC junction towards the appendage but short of it. Mostly the sinus node artery $60 \%$ of the times arise from right coronary artery and crosses the roof of the left atria towards to superior vena cava. In the rest, it arises from circumflex artery for away from the incision site.

We did not notice any difference in rhythm disturbances in our two group of patients the other is of the AV block. But as explained by the McGrath ${ }^{10}$, by keeping the incision inferiorly within the fossa ovalis and extended it to the head side of the patient parallel to the right atrial wall is a safe approach. The cephalad extension should be aiming between SVC and pulmonary vein but short of it to avoid damage to the LA roof. This also has not been noted in our series; delayed rhythm disturbances as noted by Arsiwala ${ }^{11}$, have also not been seen in a group of patients.

The ease of approach can be observed by noting that we did not need to use a specific mitral retractor to pull on the atria. We used the standard Morse retractor. While the inter atrial septum was retracted by using vein retractor which by gentle retraction we gave us a good view through which procedure could be completed. The view was mobile and retractors could be moved easily to view any specific part of the valve. Since traction of the atria is less we noted less tear and damage of the atrial wall. We found this approach as a convenient way to obtain a good result in ischemic mitral regurgitation.
It keeps the operation simple and results achievable.

\section{Conclusion}

Right atrial Trans-septal technique is a good alternative approach that can be used in relatively small atria. It not only provides an excellent exposure to the mitral valve, there also seems to be no associated rhythm disturbances encountered as well. Repeat dose of cardioplegia can be more easily administered. Putting in the juxtacommissural sutures for annuloplasty is easier. The right atrial trans-septal approach has the qualities of being used as a route by choice rather than by default.

\section{Conflict of Interest}

None

Acknowledgement

None

\section{References}

1. Levine, R. A., \& Schwammenthal, E. (2005). Ischemic mitral regurgitation on the threshold of a solution from paradoxes to unifying concepts. Circulation, 112(5), 745-758.

2. Crabtree, T. D., Bailey, M. S., Moon, M. R., Munfakh, N., Pasque, M. K., Lawton, J. S., Moazami,N., Aubuchon,K.A., AlDadah,A.S.,\& Damiano, R. J. (2008). Recurrent mitral regurgitation and risk factors for early and late mortality after mitral valve repair for functional ischemic mitral regurgitation. The Annals of thoracic surgery, 85(5), 15371543.

3. Levine, R. A., Hagége, A. A., Judge, D. P., Padala, M., Dal-Bianco, J. P., Aikawa, E., Beaudoin,J., Bischoff,J., Bouatia-Naji, N., Bruneval, P., Butcher, J. T. Alain Carpentier, Chaput, M., 
Chester,A.H.,Clusel,C.,Delling,F.N.,Die tz,H.C.,Dina,C.,Durst,R.,FernandezFriera,L.,Handschumacher,M.D.,Jensen, M.O.,Jeunemaitre,X.P.,Marec,H.L.,Tou rneau,T.L., et al (2015). Mitral valve disease [mdash] morphology and mechanisms. Nature Reviews Cardiology.

4. Braun, J., van de Veire, N. R., Klautz, R. J., Versteegh, M. I., Holman, E. R., Westenberg, J. J., Boersma,E., van der Wall,E.E.,Bax,J.J., $\quad$ Dion,R.A.E.,\& Dion, R. A. (2008). Restrictive mitral annuloplasty cures ischemic mitral regurgitation and heart failure. The Annals of thoracic surgery, 85(2), 430437.

5. Fattouch, K., Lancellotti, P., \& Angelini, G. D. (Eds.). (2015). Secondary Mitral Valve Regurgitation. Springer London.

6. Babaliaros, V. C., Green, J. T., Lerakis, S., Lloyd, M., \& Block, P. C. (2008). Emerging applications for transseptal left heart catheterization: old techniques for new procedures. Journal of the American College Cardiology, 51(22), 2116-2122.

7. García-Villarreal, O. A., GonzálezOviedo, R., Rodríguez-González, H., \& Martínez-Chapa, H. D. (2003). Superior septal approach for mitral valve surgery: a word of caution. European journal of cardio-thoracic surgery, 24(6), 862-867.

8. Doty, J. R., \& Caine, W. T. (2012). Mitral valve replacement and tricuspid valve repair through a transseptal approach for double-valve endocarditis. Multimedia Manual of Cardio-Thoracic Surgery, 2012, mms003.

9. Fagundes, W. V., \& Pinheiro, B. B. (2004). Extended vertical transseptal approach in mitral valve reoperation with a small left atrium. Revista Brasileira de Cirurgia Cardiovascular, 19(1), 29-33.

10. McGrath, L. B., Levett, J. M., \& Gonzalez-Lavin, L. (1988). Safety of the right atrial approach for combined mitral and tricuspid valve procedures. The Journal of thoracic and cardiovascular surgery, 96(5), 756-759.

11. Arsiwala, S., Parikh, P., Dixit, S., Agney, M., Kole, S., \& Saksena, D. (1992). Combined superior-transseptal approach to the mitral valve. The Annals of thoracic surgery, 53(1), 180181. 